\title{
CORRIGENDUM \\ Professor Paul H. Steen \\ 22 July 1952 - 4 September 2020 - \\ CORRIGENDUM
}

\author{
Stephen H. Davies \\ doi:10.1017/jfm.2020.958, Published by Cambridge University Press, 5 January 2021
}

The notice of Paul H. Steen's death has been updated to correct some details regarding his early career, the title of his Professorship ('Upton' changed to 'Upson') and the description of one of his research areas ('spin coating' changed to 'spin casting').

\section{REFERENCES}

Davis, S.H. 2021 Professor Paul H. Steen 22 July 1952 - 4 September 2020. J. Fluid Mech. 909, E1. doi:10.1017/jfm.2020.958. 